\title{
Case Report \\ Rare Signet Ring Cell Adenocarcinoma of the Colon Metastasis to the Orbit
}

\author{
Colin Bacorn and Lily Koo Lin \\ Department of Ophthalmology and Vision Science, University of California Davis Health, Sacramento CA, USA \\ Correspondence should be addressed to Lily Koo Lin; lklin@ucdavis.edu
}

Received 21 September 2019; Revised 3 January 2020; Accepted 8 February 2020; Published 26 February 2020

Academic Editor: Nicola Rosa

Copyright (c) 2020 Colin Bacorn and Lily Koo Lin. This is an open access article distributed under the Creative Commons Attribution License, which permits unrestricted use, distribution, and reproduction in any medium, provided the original work is properly cited.

\begin{abstract}
Metastases arising from primary tumors of the gastrointestinal tract are not commonly encountered in the orbit. Colorectal carcinomas are subcategorized based on morphological and genetic characteristics with these distinctions bearing therapeutic and prognostic significance. The behavior of these subcategories, including their propensity for orbital metastasis, differs, and clinicians treating these tumors must be aware of their metastatic profiles. This report describes a 51-year-old female with right upper lid swelling and ptosis ultimately found, what we believe to be, the first reported case of signet ring cell colon carcinoma metastasizing to the levator muscle and superior orbit. This case serves as a reminder to all clinicians to consider orbital metastasis even in malignancies not typically found in this location.
\end{abstract}

\section{Introduction}

In the largest case series of orbital tumors to date, 91 of 1264 (7\%) were metastatic [1]. The most common primary carcinomas that metastasize to the orbit are breast, prostate, and lung [2]. Orbital metastases carry a poor prognosis with an overall mean survival of 15 months [2]. Metastases from the gastrointestinal tract are very rare with only four reported cases in the Shields series [1]. In this light, it is understandable that, while primary mucinous tumors of the periorbital region have been described, there are very few reports of mucinous or signet ring cell carcinomas metastatic to the orbit from gastrointestinal primaries.

\section{Case Presentation}

A 51-year-old female initially presented with a complaint of abdominal pain and was found to have a large, obstructing, transverse colon mass. Biopsy of this lesion was consistent with a signet ring cell carcinoma. Further work up revealed biopsy-proven metastases to the retroperitoneal lymph nodes and cervix. The patient noted right upper eyelid swelling one month after the diagnosis of her colon cancer, but this was not thought to be related to her malignancy and was not initially investigated further. She underwent ileocolostomy bypass and was treated with a combination of folinic acid, fluorouracil, oxaliplatin (FOLFOX), and cetuximab with initial radiographic response.

Eight months later, the patient presented to the oculoplastics service for evaluation of her eyelid swelling. The lid swelling was painless and had not increased in size since onset. Visual acuity was 20/25 and 20/20. Pupils were without anisocoria or relative afferent pupillary defect. Extraocular motility was full in both eyes. Hertel exophthalmometry measurements at a base of $94 \mathrm{~mm}$ were $16.5 \mathrm{~mm}$ and $16 \mathrm{~mm}$ for the right and left eyes, respectively. Her palpebral fissure widths were $4 \mathrm{~mm}$ and $9 \mathrm{~mm}$ with decreased levator function of 4-5 $\mathrm{mm}$ on the right and normal levator function of $13 \mathrm{~mm}$ on the left. There was compensatory frontalis overaction. Margin-to-reflex distances were $0 \mathrm{~mm}$ and $3 \mathrm{~mm}$. Right upper eyelid fullness with a rubbery mass of the medial lid was appreciated (Figure 1). The remainder of the ophthalmic examination was unremarkable.

Given the patient's history of malignancy, she underwent magnetic resonance imaging of the orbits (Figure 2(a)) which revealed a lesion along the superior aspect of the orbit which had not been noted on surveillance imaging from one-year prior. She then underwent anterior orbitotomy for biopsy. 


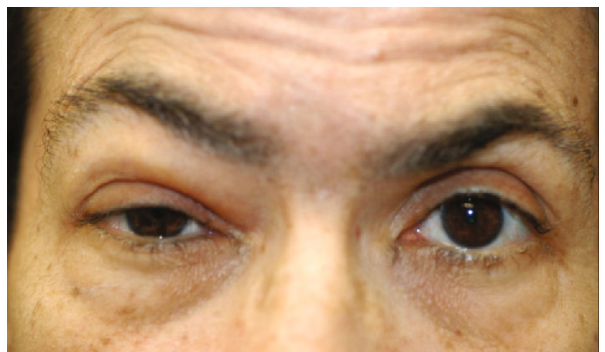

FIGURE 1: External photograph of the patient's clinical appearance on presentation demonstrating right upper eyelid fullness and ptosis.

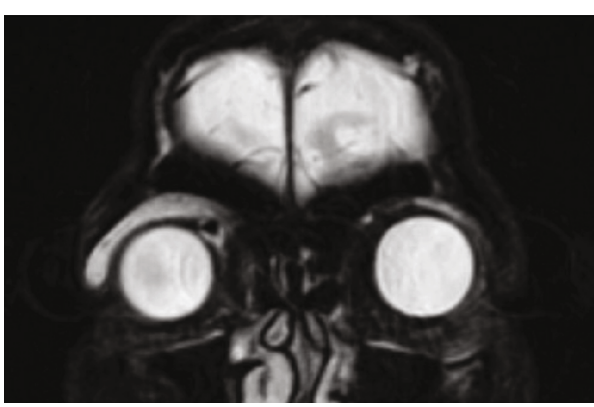

(a)

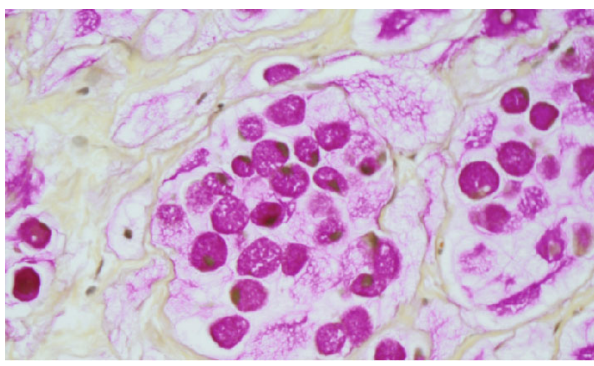

(b)

Figure 2: (a) Coronal T2-weighted fat-saturated MR images show a hyperintense mass along the right superior orbit that involves the levator complex and lacrimal gland. (b) Photomicrograph (original magnification, $\times 60$ ) of the patient's orbital biopsy specimen showing signet ring cells strongly positive for mucicarmine stain (pink).

Intraoperatively abnormal tissue was noted to infiltrate the levator muscle. Histopathology revealed dermal signet ring cells in a mucinous background (mucicarmine, CK-20, villin, CDX2 positive; CK-7 negative) consistent with metastatic signet ring cell carcinoma (Figure 2(b)). Immunohistochemistry of the lesion was very similar to that observed for the primary colon lesion (mucicarmine, CK-20 positive; villin, CDX2, CK-7 negative). The patient continued her chemotherapy regimen but eventually expired within six months of diagnosis of the orbital metastasis.

\section{Discussion}

Despite colorectal carcinoma being amongst the most common malignancies in the US, ocular and orbital metastases are extremely rare [3-5]. The World Health Organization (WHO) classification of carcinomas of the colon and rectum subcategorizes these malignancies based on histologic appearance with signet ring cell carcinoma $(>50 \%$ signet ring cells) distinguished from mucinous adenocarcinoma [6]. This distinction has clinical significance as signet ring cell carcinoma is believed to be more aggressive with a poorer prognosis [7-9]. Furthermore, the primary tumor localization (i.e., right colon, left colon, or rectum) also has an impact on prognosis $[10,11]$.

In the rare instances of metastasis to the eye or orbit, there is a predilection for the choroid with involvement in $80 \%$ of cases [12]. However, the tumors reported by Khawaja et al. arose exclusively from colorectal adenocarcinomas and none of the cases were signet ring cell carcinomas. Orbital metastasis of other subtypes of colorectal carcinomas has also been observed [13-15]. Signet ring cell tumors are an uncommon tumor subtype comprising between $0.1 \%$ and $2.4 \%$ of all colorectal carcinomas [16]. Their typical metastatic pattern is peritoneal carcinomatosis, although atypical spread through hematogenous and lymphatic pathways has also been described [17]. Review of the literature demonstrates very few reports of mucinous and signet ring cell carcinomas metastatic to the orbit from gastrointestinal primaries (three reports of each tumor type). In particular, no other case of signet ring cell carcinoma metastasizing to the orbit from a colon primary was identified $[6,18-22]$.

Primary mucinous tumors of the periorbital region have also been described. Primary mucinous tumors of the eyelids are relatively indolent and have an incidence on the order of 0.7 per million [23-26]. As both metastatic and primary mucinous tumors can present in the orbital/periorbital region distinguishing between these rare tumors can be challenging [27]. Primary mucinous tumors typically demonstrate absence of CK-20, in contrast with this patient's tumor, and this marker may aid in distinguishing primary mucinous carcinoma from metastasis [28]. Local excision via Mohs micrographic surgery may be appropriate for many cases of primary mucinous eyelid tumors but the prognosis for metastatic colorectal carcinoma is dismal, and treatment with either curative or palliative intent is typically systemic chemotherapy $[29,30]$.

Although a rare occurrence, clinicians must maintain a high index of suspicion for orbital metastasis in patients with orbital findings and a history of malignancy. 


\section{Conflicts of Interest}

The authors have no financial interests to disclose.

\section{Acknowledgments}

The authors thank Rebecca Sonu MD (El Dorado Pathology Medical Group, Placerville, CA) for her help with the histopathology image for this case.

\section{References}

[1] J. A. Shields, C. L. Shields, and R. Scartozzi, "Survey of 1264 patients with orbital tumors and simulating lesions: the 2002 Montgomery Lecture, part 1," Ophthalmology, vol. 111, no. 5, pp. 997-1008, 2004.

[2] J. A. Shields, C. L. Shields, H. K. Brotman, C. Carvalho, N. Perez, and R. C. Eagle Jr., "Cancer metastatic to the orbit: the 2000 Robert M. Curts Lecture," Ophthalmic Plastic and Reconstructive Surgery, vol. 17, no. 5, pp. 346-354, 2001.

[3] R. L. Siegel, K. D. Miller, and A. Jemal, "Cancer statistics, 2019," CA: A Cancer Journal for Clinicians, vol. 69, no. 1, pp. 7-34, 2019.

[4] J. R. Robinson, P. A. Newcomb, S. Hardikar, S. A. Cohen, and A. I. Phipps, "Stage IV colorectal cancer primary site and patterns of distant metastasis," Cancer Epidemiology, vol. 48, pp. 92-95, 2017.

[5] A. P. Ferry and R. L. Font, "Carcinoma metastatic to the eye and orbit. I. A clinicopathologic study of 227 cases," Archives of Ophthalmology, vol. 92, no. 4, pp. 276-286, 1974.

[6] B. K. Monson, B. C. K. Patel, and C. H. Kim, "Metastatic mucinous adenocarcinoma of the orbit," Orbit, vol. 30, no. 1, pp. 18-20, 2011.

[7] F. T. Bosman, World Health Organization, and International Agency for Research on Cancer, WHO Classification of Tumours of the Digestive System, International Agency for Research on Cancer, Lyon, 4th edition, 2010.

[8] P. Y. Park, T. Goldin, J. Chang, M. Markman, and M. N. Kundranda, "Signet-ring cell carcinoma of the colon: a case report and review of the literature," Case Reports in Oncology, vol. 8, no. 3, pp. 466-471, 2015.

[9] F. Benedix, D. Kuester, F. Meyer, and H. Lippert, "Einfluss des muzinösen und siegelringzelligen Subtyps auf epidemiologische, histologische und molekularbiologische Eigenschaften sowie auf die Prognose des kolorektalen Karzinoms," Zentralblatt für Chirurgie, vol. 138, no. 4, pp. 427-433, 2013.

[10] S. Stintzing, S. Tejpar, P. Gibbs, L. Thiebach, and H.-J. Lenz, "Understanding the role of primary tumour localisation in colorectal cancer treatment and outcomes," European Journal of Cancer, vol. 84, pp. 69-80, 2017.

[11] N. Boeckx, K. Janssens, G. van Camp et al., "The predictive value of primary tumor location in patients with metastatic colorectal cancer: a systematic review," Critical Reviews in Oncology/Hematology, vol. 121, pp. 1-10, 2018.

[12] M. R. Khawaja, J. T. Minturn, A. J. Spittler, and E. G. Chiorean, "Ocular metastasis of colorectal cancer: an uncommon presentation of a common malignancy," Hematology/Oncology and Stem Cell Therapy, vol. 8, no. 4, pp. 176-180, 2015.

[13] S. Pal, K. Bose, A. Sharma, and M. Sikdar, "Orbital metastasis from rectal adenocarcinoma-report of a rare case," Iranian Journal of Pathology, vol. 11, no. 5, pp. 474-477, 2016.
[14] E. B. Ludmir, S. J. McCall, B. G. Czito, and M. Palta, "Radiosensitive orbital metastasis as presentation of occult colonic adenocarcinoma," BML Case Reports, vol. 2014, no. 2, article bcr2014206407, 2014.

[15] W. V. Lin, P. Chévez-Barrios, A. Sadaka, and A. G. Lee, "Orbital metastasis mimicking internuclear ophthalmoplegia: a case report and review," Canadian Journal of Ophthalmology, vol. 52, no. 4, pp. e149-e151, 2017.

[16] T. Anthony, R. George, M. Rodriguez-Bigas, and N. J. Petrelli, "Primary signet-ring cell carcinoma of the colon and rectum," Annals of Surgical Oncology, vol. 3, no. 4, pp. 344-348, 1996.

[17] M. Morales-Cruz, N. Salgado-Nesme, A. M. Trolle-Silva, and J. H. Rodriguez-Quintero, "Signet ring cell carcinoma of the rectum: atypical metastatic presentation," BMJ Case Reports, vol. 12, no. 4, article e229135, 2019.

[18] K. T. Oh, M. Alford, R. J. Kotula, and J. A. Nerad, "Adenocarcinoma of the esophagus presenting as orbital cellulitis," Archives of Ophthalmology, vol. 118, no. 7, pp. 986-988, 2000.

[19] T. Chekrine, A. Hassouni, M. Hatime et al., "Orbital metastasis from mucinous adenocarcinoma of the rectum," Journal Français d'Ophtalmologie, vol. 36, no. 5, pp. e73-e75, 2013.

[20] R. B. Hisham, H. Thuaibah, and Y. A. Gul, "Mucinous adenocarcinoma of the rectum with breast and ocular metastases," Asian Journal of Surgery, vol. 29, no. 2, pp. 95-97, 2006.

[21] J. J. Yunker, M. G. Vicinanzo, R. A. Braswell, R. W. Read, G. F. Goldin, and J. A. Long, "Unusual presentation of gastric adenocarcinoma metastatic to the orbit," Ophthalmic Plastic and Reconstructive Surgery, vol. 22, no. 6, pp. 490-491, 2006.

[22] N. C. Charles, D. D. Ng, and C. I. Zoumalan, "Signet cell adenocarcinoma of the rectum metastatic to the orbit," Ophthalmic Plastic and Reconstructive Surgery, vol.28, no. 1, pp.e1-e2, 2012.

[23] M. S. Baker, V. T. Yin, D. Ivan et al., "Epidemiology and prognosis of primary periocular sweat gland carcinomas," Ophthalmic Plastic and Reconstructive Surgery, vol. 33, no. 2, pp. 101-105, 2017.

[24] Z. S. Tannous, M. M. Avram, A. Zembowicz et al., "Treatment of synchronous mucinous carcinoma and endocrine mucinproducing sweat gland carcinoma with Mohs' micrographic surgery," Dermatologic Surgery, vol. 31, no. 3, pp. 364-367, 2005.

[25] M. Friednash, L. Golitz, and T. Bohlmeyer, "Periorbital solitary nodule and multiple small papules in a 63-year-old Woman," Archives of Dermatology, vol. 133, no. 9, pp. 1161-1162, 1997.

[26] L. Breiting, L. Christensen, K. Dahlstrøm, V. Breiting, and J. F. Winther, "Primary mucinous carcinoma of the skin: a population-based study," International Journal of Dermatology, vol. 47, no. 3, pp. 242-245, 2008.

[27] R. Cecchi and V. Rapicano, "Primary cutaneous mucinous carcinoma: report of two cases treated with Mohs' micrographic surgery," The Australasian Journal of Dermatology, vol. 47, no. 3, pp. 192-194, 2006.

[28] F. Eckert, U. Schmid, T. Hardmeier, and M. Altmannsberger, "Cytokeratin expression in mucinous sweat gland carcinomas: an immunohistochemical analysis of four cases," Histopathology, vol. 21, no. 2, pp. 161-165, 1992.

[29] G. Marrazzo, R. B. Thorpe, and W. H. Black, "Primary mucinous carcinoma of the eyelid treated with Mohs micrographic surgery," Cutis, vol. 100, no. 5, pp. E7-E10, 2017.

[30] N. Ikoma, K. Raghav, and G. Chang, "An update on randomized clinical trials in metastatic colorectal carcinoma," Surgical Oncology Clinics of North America, vol. 26, no. 4, pp. 667-687, 2017. 